\title{
PASSIVE FIELD MONITORING OF PLUTONIUM AND AMERICIUM IN SOIL*
}

\author{
R. B. Gammage, K. E. Meyer, and C. S. Dudney \\ Health Sciences Research Division \\ Oak Ridge National Laboratory \\ P.O. Box 2008, Oak Ridge, TN, USA 37831-6379
}

\author{
To be published in the Proceedings \\ of the Second International Symposium and Exhibition \\ on Environmental Contamination in Central and Eastern Europe \\ September 20-23, 1994
}

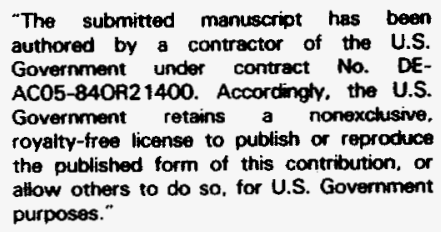

DISCLAIMER

\begin{abstract}
This report was prepared as an account of work sponsored by an agency of the United States Government. Neither the United States Government nor any agency thereof, nor any of their employees, makes any warranty, express or implied, or assumes any legal liability or responsibility for the accuracy, completeness, or usefulness of any information, apparatus, product, or process disclosed, or represents that its use would not infringe privately owned rights. Reference herein to any specific commercial product, process, or service by trade name, trademark, manufacturer, or otherwise does not necessarily constitute or imply its endorsement, recommendation, or favoring by the United States Government or any agency thereof. The views and opinions of authors expressed herein do not necessarily state or reflect those of the United States Government or any agency thereof.
\end{abstract}

*Research sponsored by the Office of Technology Development under TTP \# OR-15-PR-38 under Martin Marietta Energy Systems Inc., contract DE-AC05-84OR21400 with the U.S. Department of Energy. 


\section{DISCLAIMER}

Portions of this document may be illegible in electronic image products. Images are produced from the best available original document. 


\title{
PASSIVE FIELD MONITORING OF PLUTONIUM AND AMERICIUM IN SOIL"
}

\author{
R. B. Gammage, K. E. Meyer, and C. S. Dudney \\ Health Sciences Research Division \\ Oak Ridge National Laboratory \\ P.O. Box 2008, Oak Ridge, TN, USA $37831-6379$
}

\begin{abstract}
$\underline{\text { Abstract }}$
Our progress is described in applying passive alpha track detectors (ATDs) and electret ion chambers (EICs) to in-situ field monitoring of soils contaminated with particulate plutonium and americium at a desert site. By varying the exposure times, from a few minutes to about one day, we quantitatively measured alpha activity varying between $\sim 100 \mathrm{pCi} / \mathrm{g}$ and $\sim 100 \mathrm{nCi} / \mathrm{g}$. Suggested applications are definition of the boundaries of contamination zones and verification that post-remediated soils are below release limits.
\end{abstract}

\section{Introduction}

At the first Budapest symposium on Environmental Contamination in Central and Eastern Europe, we reported on our preliminary attempts to make passive, in-situ measurements of alpha activity in soils contaminated with plutonium. [1] A "safety shot" conducted in 1955, in an area known as 11B at the Nevada Test Site (NTS), caused the contamination. This communication reports on our efforts to make field measurements on soils with activities ranging over about three orders of magnitude. In particular, we are trying to find niches where the passive, integrating detectors can provide needed information not readily obtainable by other in-situ monitoring techniques.

\section{Methods}

The alpha track detector (ATD) and electret ion chamber (EIC) were described previously. [1] When making a surface measurement in the field, the soil surface was prepared by removing extraneous vegetation and rocks and them tamping the soil with the sole of one's boot to make a flat surface.

To deploy an ATD, the protective polyethylene film was peeled from one face and the exposed face placed face down against the soil. A wooden block was used to weight down the ATD. The block's function was to stop the small plastic ATD from shifting or blowing away, prevent baking in the sun, and give protection from rain. The wood also provided thermal mass and insulation for reducing moisture condensation, especially at night when the temperature falls below the dew point. The retrieved ATD was sequentially rinsed with water to remove adhering soil, then air dried, radiation checked, wrapped with polyethylene film, sealed in a Mylar bag and mailed to the manufacturer, Landauer, Inc., for processing. Readings were given as etch tracks per $\mathrm{mm}^{2}$. The track generation rate is proportional to soil activity.

To deploy an EIC, the lower edge of the chamber portion was firmly pressed into the soil to obtain a seal. An electret was read for initial voltage and then screwed into the top of the seated chamber to initiate exposure. To

*Research sponsored by the Office of Technology Development under TTP \# OR-15-PR-38 under Martin Marietta Energy Systems Inc., contract DE-AC05-84OR21400 with the U.S. Department of Energy. 
terminate exposure, the electret was unscrewed and its voltage reread with a hand-held voltmeter. The EIC response is expressed as voltage drop per hour. The rate of voltage drop is proportional to soil activity.

The measurement periods depended on the contaminant activity at a particular location; exposures varied between 5 minutes and 3 days. Sets of 3 ATDs and 3 EICs were usually deployed at each location over an area of about $0.5 \mathrm{~m}^{2}$. On some occasions, "screened" EICs were deployed at the same time. The screen was a closely fitting, circular Tyvek sheet placed on the ground inside the chamber to block alpha radiation coming directly from the soil. The Tyvek, however, is pervious to radon gas passing out of the soil. These "screened" measurements enable one to evaluate and correct for the effects of radon and radon daughter buildup in the EICs.

Field measurements to estimate background effects were also made on the ground adjacent to a car park about 1 $\mathrm{km}$ from the location of the safety shot to establish local background levels.

Detector calibration factors were established using soils collected along the contamination fenceline at Area $11 \mathrm{~B}$ and returned to Oak Ridge National Laboratory for analyses. Processing and analytical procedures are discussed elsewhere. [2]

\section{Results and Discussion}

A schematic is shown in Fig. 1 of that portion of Area $11 \mathrm{~B}$ where we made our measurements. The contours are isopleths of Pu-239 + Am-241 interpolated from in-situ gamma spectroscopy measurements conducted 25 feet above groundlevel; [3] the ${ }^{239} \mathrm{Pu}{ }^{24} \mathrm{Am}$ ratio is 6.9. The dotted line is the fenceline of the contamination zone. The solid points 01 to 09 are positions along the fenceline where we made in-situ alpha measurements and collected soil samples. The grid points, $E_{2}, E_{3},-G_{4}$, etc., are surveyed positions.

\section{In-Situ Measurement Locations, Nevada Test Site area $11-B$}

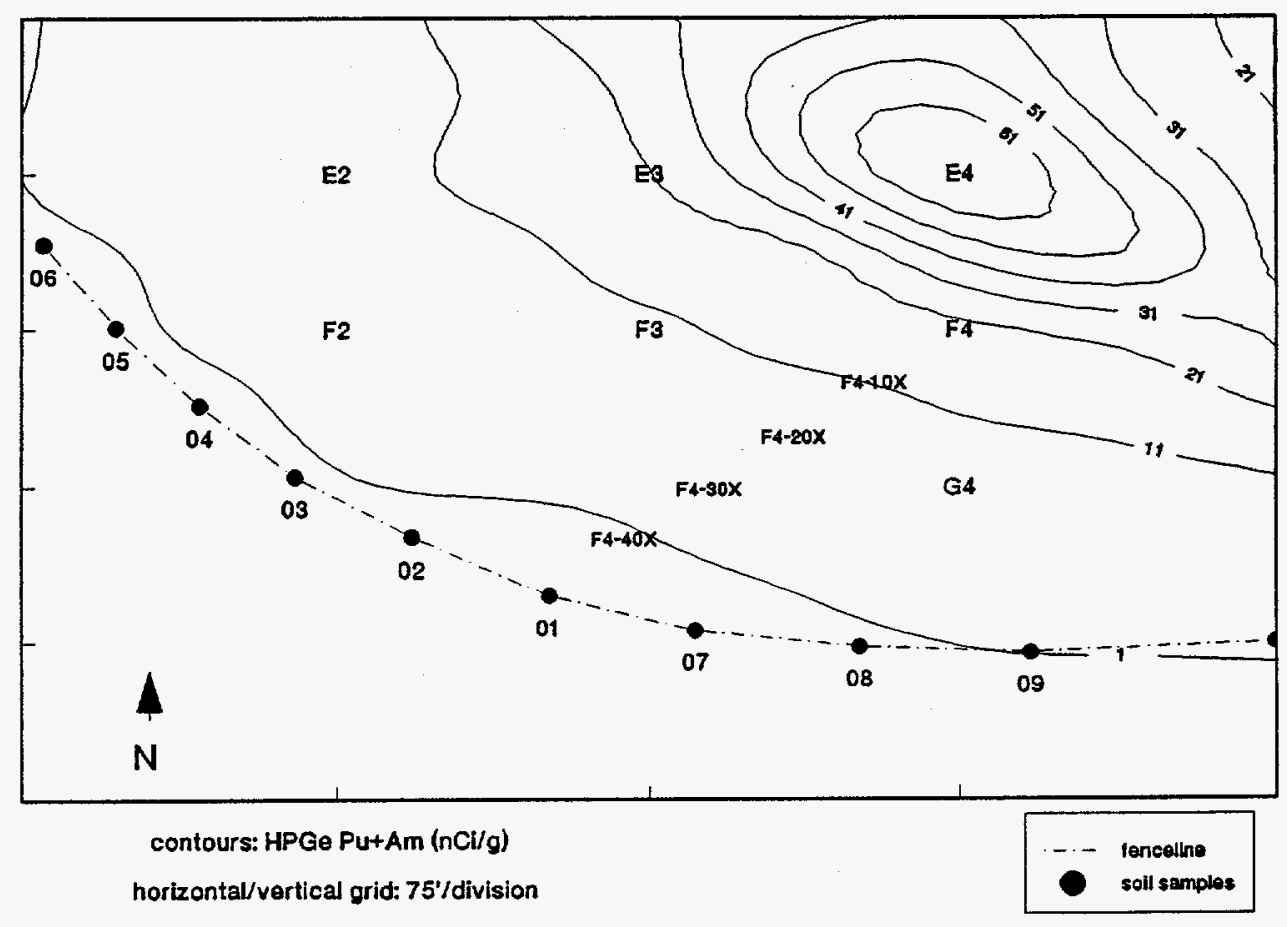

Fig. 1. Schematic of Area $1 \mathrm{lB}$ at the Nevada Test Site. Contours are surface Pu + Am contamination levels interpolated from in-situ gamma spectroscopy measurements.[3] 
(a) EIC Nevada Test Site Calibration

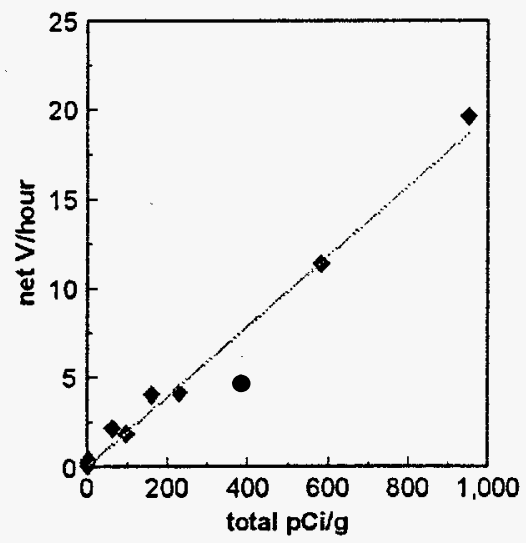

(b) ATD Nevada Test Site Calibration

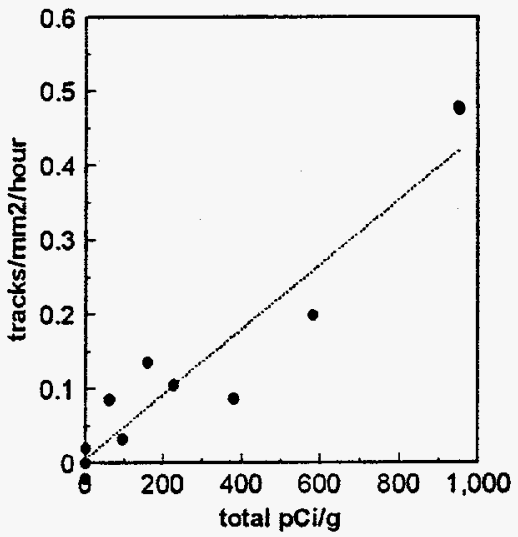

Fig. 2. Laboratory calibration curves obtained on processed NTS soils.

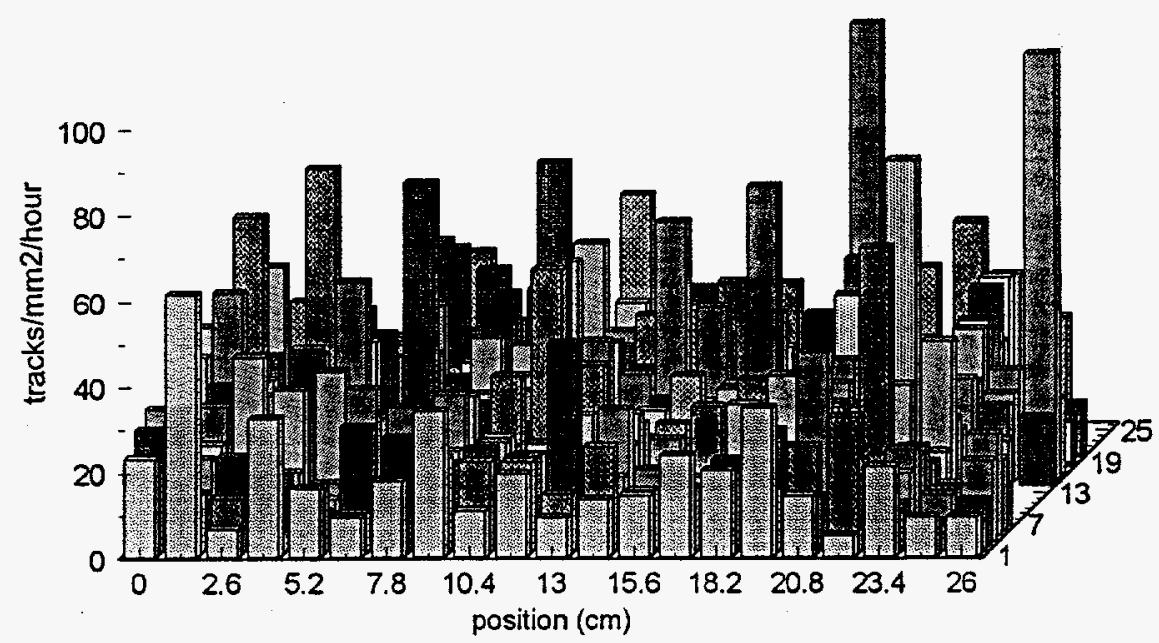

Fig. 3. Spatial inhomogeneity in surface alpha activity encountered at position F4. 
The calibration curves for the EIC and ATD devices are shown in Figs. 2a and 2b, respectively.

Total activities were determined by radiochemical analyses for $\mathrm{Pu}-239, \mathrm{Pu}-240$, and Am-241. The soils were very inhomogeneous in alpha activity. Even after milling each soil for several hours, and then analyzing ten $0.5 \mathrm{~g}$ aliquots, standard deviations ranged from $5 \%$ to $29 \%$.

The sub-cm scale inhomogeneity that we encountered during surface measurements is demonstrated in Fig. 3. This particular in-situ measurement was made by placing a $25 \mathrm{~cm} \times 25 \mathrm{~cm}$ sheet of ATD face down at position F4 for an hour. Within this small area, alpha activity varies by more than ten-fold.

Because the alpha activity is so variable on a small (sub-cm) scale, one anticipates that in-situ measurements with different types of devices, that are placed side by side at a particular location, will indeed give substantially different results. This prediction is borne out by comparing the in-situ field measurements listed in Table 1.

Table 1. Comparison of surface contamination measurements.

\begin{tabular}{|c|c|c|c|c|}
\hline Position & EIC nCi/g & ATD nCi/g & $\begin{array}{c}\text { Gamma } \\
\text { Spectroscopy } \\
\text { nCi/g } \\
\end{array}$ & $\begin{array}{c}\text { Radiochemical } \\
\text { nCi/g }\end{array}$ \\
\hline E4 & $60.4 \pm 18.9$ & $263 \pm 95$ & 92.4 & --- \\
\hline $\mathrm{F} 4$ & $26.1 \pm 5.7$ & $76.0 \pm 21.0$ & 24.6 & $\cdots$ \\
\hline F4-10X & $9.3 \pm 3.0$ & $24.9 \pm 20.5$ & 17.6 & $\ldots$ \\
\hline F4-20X & $6.5 \pm 3.9$ & $12 . \pm 7.3$ & 8.2 & $\ldots$ \\
\hline F4-30X & $1.8 \pm 0.4$ & $6.1 \pm 5.5$ & 3.5 & $\ldots$ \\
\hline F4-40X & $0.89 \pm 0.79$ & $3.6 \pm 4.2$ & 1.2 & -- \\
\hline fenceline 01 & $0.16 \pm 0.04$ & $0.25 \pm 0.10$ & $\ldots$ & 0.08 \\
\hline 02 & $0.34 \pm 0.13$ & $0.27 \pm 0.31$ & $\cdots$ & $\cdots$ \\
\hline 03 & $0.25 \pm 0.13$ & $0.34 \pm 0.22$ & --- & $\cdots$ \\
\hline 04 & $0.89 \pm 0.21$ & $1.76 \pm 1.37$ & $\ldots$ & 0.77 \\
\hline 05 & $0.12 \pm 0.05$ & $0.28 \pm 0.27$ & $-\cdots$ & 0.16 \\
\hline 06 & $0.13 \pm 0.07$ & $0.29 \pm 0.13$ & -- & $\ldots$ \\
\hline 07 & $0.14 \pm 0.08$ & $0.26 \pm 0.14$ & $\ldots$ & 0.38 \\
\hline 08 & $0.38 \pm 0.24$ & $0.37 \pm 0.16$ & $\cdots$ & $\ldots$ \\
\hline 09 & $0.32 \pm 0.14$ & $0.44 \pm 0.34$ & $\ldots$ & 0.23 \\
\hline
\end{tabular}

In several instances, the variation is close to $100 \%$ for in-situ measurements with devices of a particular type that are placed side by side. This variability is again attributable to spatially inhomogeneous contamination. The variability in measurement can be nearly eliminated if repeat measurements are made at the same spot without disturbing the detector's position on the soil. This can be done, for example, by leaving the chamber of the EIC 
in place on the soil and making repeat measurements by screwing in and then unscrewing only the electret unit. The readings are then reproducible with a variability of less than $5 \%$.

Intercomparison of results between the different methods (Table 1) indicate that at particular locations, two- or three-fold differences in alpha activity are common within an area of about $0.5 \mathrm{~m}^{2}$. Again this variability does not surprise us, given the aforementioned spatial inhomogeneity. There is, however, an indication of bias to higher alpha activity measured by the ATD technique. The cause may be linked to much of the alpha contamination being in particulate form; $[1,2]$ the ATD technique is currently optimized to read single tracks rather than clusters of etch tracks deriving from hot particles. We are currently trying to improve our ability to count tracks that appear in clusters.

\section{Conclusions}

Two types of passive monitors are useful for making in-situ surface measurement on desert soils contaminated with plutonium and americium. Spatial inhomogeneities on a small scale (sub-cm) can be detected. Exposure times of one day permit one to quantify alpha activities of $100 \mathrm{pCi} / \mathrm{g}$ or less. The passive monitors offer an inexpensive means of defining the boundaries of a contamination zone. In a post-cleanup situation, passive monitoring will be a convenient way of verifying that residual soils are as free of alpha activity and hot particles as they need to be.

\section{References:}

[1] Gammage, R. B., DePriest, J.C., Wheeler, R.V., Dempsey, J.C., and Kotrappa, P., "Monitoring of Surface Alpha Contamination with Inexpensive Passive Monitors," to be published in Proc. Second International Symposium on Environmental Contamination in Central and Eastern Europe (1995).

[2] Meyer, K.E., Gammage, R.B., Dudney, C.S., Reed-Walker, S., Kotrappa, P., Wheeler, R.V., and Salasky, M. "Field Measurements of Pu and Am Contamination in Soils at the Nevada Test Site Using Passive Alpha Detectors, Radioactivity and Radiochemistry," 5(2), p. 66 (1994).

[3] Colton, D., "An In Situ Radiological Survey of Area 11 Nuclear Safety Test Locations, Sites A, B, and C, Nevada Test Site, Central Nevada, Conducted May 4 through June 10, 1992," EG\&G/EM letter report to U.S. Department of Energy Nevada Operations Office; NRD-93-330 (1993). 